\title{
A Dominant Mutation in a Neuronal Acetylcholine Receptor Subunit Leads to Motor Neuron Degeneration in Caenorhabditis elegans
}

\author{
Belinda Barbagallo, Hilary A. Prescott, ${ }^{\star}$ Patrick Boyle, ${ }^{\star}$ Jason Climer, and Michael M. Francis \\ Department of Neurobiology, University of Massachusetts Medical School, Worcester, Massachusetts 01605
}

\begin{abstract}
Inappropriate or excessive activation of ionotropic receptors can have dramatic consequences for neuronal function and, in many instances, leads to cell death. In Caenorhabditis elegans, nicotinic acetylcholine receptor (nAChR) subunits are highly expressed in a neural circuit that controls movement. Here, we show that heteromeric nAChRs containing the acr- 2 subunit are diffusely localized in the processes of excitatory motor neurons and act to modulate motor neuron activity. Excessive signaling through these receptors leads to cell-autonomous degeneration of cholinergic motor neurons and paralysis. C. elegans double mutants lacking calreticulin and calnexintwo genes previously implicated in the cellular events leading to necrotic-like cell death (Xu et al. 2001) - are resistant to nAChRmediated toxicity and possess normal numbers of motor neuron cell bodies. Nonetheless, excess nAChR activation leads to progressive destabilization of the motor neuron processes and, ultimately, paralysis in these animals. Our results provide new evidence that chronic activation of ionotropic receptors can have devastating degenerative effects in neurons and reveal that ion channel-mediated toxicity may have distinct consequences in neuronal cell bodies and processes.
\end{abstract}

\section{Introduction}

Roles for ionotropic receptor-mediated signaling in the nervous system extend far beyond a well characterized participation in cell-cell communication at synapses. Ionotropic receptor activation is one of several key factors that influence cell survival in developing and mature nervous systems. For example, signaling through nicotinic acetylcholine receptors (nAChRs) promotes the elimination of neurons in the developing avian autonomic nervous system (Hruska and Nishi, 2007; Hruska et al. 2009), and inappropriate pharmacological activation of nAChRs in the Caenorhabditis elegans nervous system leads to developmental arrest (Ruaud and Bessereau, 2006). In the mature nervous system, inappropriate or excessive ion channel activation can have dramatic consequences. In mammals, hypoxic events, such as stroke, lead to excitotoxic cell death as a consequence of excess glutamate release and hyperexcitation of ionotropic glutamate receptors (iGluRs) (Sattler and Tymianski, 2001). Likewise, mutations that cause prolonged activation of nAChRs or iGluRs can lead to neu-

\footnotetext{
Received March 23, 2010; revised June 9, 2010; accepted Aug. 21, 2010.

This work was supported by a grant from the Worcester Foundation for Biomedical Research (M.M.F.) and by National Institutes of Health Grant NS064263 (M.M.F.). Some nematode strains used in this work were provided by the Caenorhabditis Genetics Center, which is funded by the National Institutes of Health National Center for Research Resources. We thank Andrew Fire for GFP vectors, Yuji Kohara for cDNA clones, the C. elegans Gene Knockout Consortium for deletion mutants, David Madsen for technical assistance in generating the full-length ACR-2::GFP clone, Lindsey Soll for help with imaging the coexpression of Pnmr-1::mCherry and Punc-17::GFP, and Mark Alkema and Claire Benard for critically reading the manuscript and helpful discussions. *H.A.P. and P.B. contributed equally to this work.

Correspondence should be addressed to Michael M. Francis, Department of Neurobiology, 715 Lazare Research Building, University of Massachusetts Medical School, 364 Plantation Street, Worcester, MA 01605. E-mail: michael.francis@umassmed.edu.

DOI:10.1523/JNEUROSCI.1515-10.2010

Copyright $\odot 2010$ the authors $\quad 0270-6474 / 10 / 3013932-11 \$ 15.00 / 0$
}

rodegeneration and cell death in organisms ranging from nematodes to mammals (Treinin and Chalfie, 1995; Zuo et al. 1997; Heintz and Zoghbi, 2000; Orr-Urtreger et al. 2000; Labarca et al. 2001; Orb et al. 2004; Miwa et al. 2006). Excess ion channel activation is also a contributing factor in neurodegenerative diseases. For example, the selective vulnerability of motor neurons to cell death in amyotrophic lateral sclerosis (ALS) is believed to arise, at least in part, from hyperactivation of calcium-permeable AMPAtype iGluRs (Kwak and Weiss, 2006; Grosskreutz et al. 2010). Interestingly, in various mouse models of motor neuron diseases, including ALS, genetic manipulations that prevent the death of motor neuron cell bodies are not successful in halting disease progression (Sagot et al. 1995; Gould et al. 2006). This result implies that ion channel hyperactivation may contribute to degenerative events that persist even under conditions when neuronal cell death is attenuated. Shared features of ion channel-mediated degeneration across these diverse receptor types and systems suggest that aspects of this process may be broadly conserved across organisms (Driscoll and Gerstbrein, 2003). In most cases, however, a cohesive picture of the cellular events that influence the progression toward cell death as a consequence of ion channel hyperactivation remains unclear.

Ionotropic receptor signaling and its contribution to neurodegeneration can be dissected in detail in the compact nervous system of the nematode Caenorhabditis elegans. Here, we provide evidence that the non- $\alpha$ nAChR subunit ACR- 2 contributes to a heteromeric receptor that is important for regulating the activity of excitatory motor neurons. A pore modification in ACR-2 leads to loss of motor neurons and paralysis of the animal. Genetic ablation of $\mathrm{nAChR}$ subunits that coassemble into a heteromeric receptor complex with ACR-2 suppresses ACR-2(L/S) (where L/S 
is leucine-to serine substitution) toxicity. In addition, C. elegans double mutants lacking two genes previously implicated in calcium homeostasis and necrotic cell death (crt-1/calreticulin and $c n x-1 /$ calnexin) are resistant to $\mathrm{nAChR}$-mediated toxicity and possess normal numbers of motor neuron cell bodies. Nonetheless, we observe a progressive degeneration of the motor neuron processes that leads to paralysis in these animals. Thus, ion channel hyperactivation has distinct consequences for neuronal cell bodies and processes.

\section{Materials and Methods}

\section{Molecular biology}

AChR subunit constructs. The full-length ACR-2::GFP transgene (pDM1232) was generated by introducing the green fluorescent protein (GFP) coding sequence in-frame into the sequence of an acr-2 genomic fragment ( -3353 to +7776 bp relative to the translational start site) encoding the intracellular loop between transmembrane domains TM3 and TM4. The full-length ACR-2(L/S) construct (pBB9) was generated by PCR-based site directed mutagenesis using mutant primers and pDM1232 as the template. The Pacr-2::ACR-12 cDNA (pHP3) and Punc-47::ACR-12 cDNA (pBB25) constructs were generated by amplifying the acr-12 cDNA from the expressed sequence tag yk1093d12 (gift from Yuji Kohara, National Institute of Genetics, Mishima, Japan) using sequence-specific primers designed to the start and stop of acr-12 and subcloning it into the NheI/SacI sites of a plasmid containing an $\sim 3.3 \mathrm{~kb}$ promoter for the $a c r-2$ gene or into a plasmid containing a $1.3 \mathrm{~kb}$ promoter for the unc- 47 gene.

Transcriptional reporters. The Punc-47::mCherry construct (pPRB5) was generated by subcloning an AgeI/AatII fragment that contained the full-length mCherry coding sequence into a vector containing a $1.3 \mathrm{~kb}$ promoter for the unc-47 gene. The Pacr-2::GFP (pPRB19) construct was generated by subcloning an AatI/BamHI fragment that contained an $\sim 3.3 \mathrm{~kb}$ promoter for the acr-2 gene into a vector containing the GFP coding sequence.

\section{C. elegans strains}

C. elegans strains were grown on nematode growth medium (NGM) plates with the OP50 strain of Escherichia coli at $22^{\circ} \mathrm{C}$ using standard laboratory procedures. Wild-type animals are the N2 Bristol strain. All transgenic strains were obtained by microinjection of plasmid DNA into the germ line and data presented are from a single representative transgenic line unless noted otherwise. In all cases, lin-15(n765ts) mutants were injected with the lin-15 rescuing plasmid (pL15EK; $30 \mathrm{ng} / \mu \mathrm{l}$ ) and one or more of the following plasmids (30 ng/ $\mu \mathrm{l})$ : pBB9, pBB25, pDM1232, pHP3, pPRB4, pPRB5, pPRB14, pPRB19. Multiple independent extragenic lines were obtained for each transgenic strain. Stably integrated lines were generated as necessary by $x$-ray integration and outcrossed at least four times to wild type. The transgenic strain expressing the integrated ACR-2(L/S) transgene (ufIs25) was outcrossed 10 times to wild type. The following strains were used in this study: RB1559 acr-2(ok1887), IZ421 acr-12(ok367), RB2071 ced-3(ok2734), VC1801 cnx-1(ok2234), RB1021 crt-1(ok948), IZ74 unc-29(x29), CB904 unc38(e264), CB306 unc-50(e306), VC731 unc-63(ok1075), CB883 unc74(e883), IZ380 ufIs31, IZ814 ufIs25, IZ625 ufIs25;ufIs31, IZ790 ufIs49, IZ627 ufIs42, LX949 vsIs48, IZ924 ufIs25;vsIs48, IZ950 ced-3(ok2734); ufIs25;vsIs48, IZ877 cnx-1(ok2234);ufIs25;vsIs48, IZ926 crt-1(ok948); ufIs25;vsIs48, IZ976 crt-1(ok948);cnx-1(ok2234); ufIs25;vsIs48, IZ971 crt-1(ok948);cnx-1(ok2234);vsIs48, IZ927 crt-1(ok948);cnx-1(ok2234); ufIs42, IZ787 unc-29(x29);ufIs25, IZ928 acr-3(ok2049);ufIs265, IZ929 acr-5(ok180); ufIs25, IZ930 acr-9(ok933); ufIs25, IZ931 acr-19(ok967); ufIs25, IZ932 acr-23(ok2840);ufIs25,IZ446 unc-38(e264);ufIs25, IZ659 unc-50(e306);ufIs25, IZ921 unc-63(ok1075);ufIs25, IZ490 unc-68(e540); ufIs25, IZ604 unc-74(e883);ufIs25, IZ673 acr-12(ok367);ufIs25; ufEx148, IZ937 acr-12(ok367);ufIs25; ufIs60, IZ861 acr-12(ok367);ufIs25;ufEx191.

\section{Genetic screen and identification of suppressors of}

ACR-2(L/S)-induced paralysis

Paralyzed animals expressing the integrated ACR-2(L/S) array (ufIs25) were mutagenized with $50 \mathrm{~mm}$ ethyl methanesulfonate (Brenner, 1974).
Young adult F2 progeny of $\sim 20,000$ mutagenized animals were washed twice with M9 and transferred to fresh plates. After allowing time for the animals to disperse, moving animals were picked to single plates. Eightyone candidate suppressors were isolated. A secondary screen showed that fifty-one of these were resistant to the paralyzing effects of levamisole. For genetic complementation tests, males carrying a mutation in candidate levamisole-resistance genes were crossed with hermaphrodites carrying the ACR-2(L/S) transgene and a suppressor mutation. F1 progeny were scored for paralysis. A cross was performed in parallel using N2 males to identify X-linked suppressor mutations and determine dominance/recessivity. The mapping of acr-12 alleles was performed in the presence of the ACR-2(L/S) transgene. A strain carrying the integrated ACR-2(L/S) transgene (ufIs25) on linkage group I was backcrossed $7 \times$ to the CB4856 Hawaiian strain. acr-12 alleles were mapped to a region the right of +8 on the $\mathrm{X}$ chromosome using the SNP mapping procedure described as previously (Wicks et al. 2001; Davis et al. 2005).

\section{Behavioral assays}

All behavioral analysis was performed with young adult animals $(24 \mathrm{~h}$ post-L4) at room temperature $\left(22^{\circ} \mathrm{C}-24^{\circ} \mathrm{C}\right)$; different genotypes were scored in parallel, with the researcher blinded to the genotype.

Aldicarb and levamisole assays. Staged populations of adult animals $(\sim 10)$ were transferred to NGM plates containing $1 \mathrm{~mm}$ aldicarb (ChemService), and movement was assessed every $15 \mathrm{~min}$ for $2 \mathrm{~h}$. Data represent the mean \pm SEM of at least four assays. For levamisole assays, staged populations of adult animals were scored for paralysis after $120 \mathrm{~min}$ on plates containing $200 \mu \mathrm{M}$ levamisole.

Body bend analysis. Body bends were scored on unseeded NGM agar. Animals were transferred from their culture plate to an unseeded plate and allowed to crawl away from any food that might have been transferred. The animals were then gently transferred without food to another unseeded plate and allowed to recover for $1 \mathrm{~min}$. After the recovery period, the animals were filmed for 5 min using an ImagingSource DMK 21F04 FireWire camera and iMovie software.

\section{Microscopy}

Confocal microscopy was performed using a Zeiss Axioskop 2 microscope system and LSM Pascal 5 imaging software (Zeiss). Images were processed using ImageJ software (open source). Epifluorescent imaging was performed using a Zeiss Axioimager M1 microscope and Axiovision software (Zeiss). Movies and still images for behavioral analyses were obtained using an Olympus SZ61 upright microscope equipped with a FireWire camera (ImagingSource). For the developmental timeline, synchronized populations were obtained by bleaching gravid animals on NGM plates seeded with OP50. The resulting progeny were allowed to mature at room temperature. Animals were imaged at 16, 28, 38, and $48 \mathrm{~h}$ after bleaching using wide-field epifluorescent microscopy, and the number of surviving cell bodies were counted manually with the researcher blinded to genotype.

\section{Results}

\section{acr-2 encodes a nicotinic receptor subunit expressed in} cholinergic motor neurons

The C. elegans genome encodes 29 nAChR subunits that contribute to the formation of distinct classes of homopentameric and heteropentameric receptors (Jones et al. 2007; Rand, 2007). Two classes of nAChRs formed from six of these subunits are expressed in body wall muscle cells and required for neuromuscular signaling (Richmond and Jorgensen, 1999; Francis et al. 2005; Touroutine et al. 2005). Previous studies have suggested that the expression of several nicotinic acetylcholine receptor subunits, including the non- $\alpha$ subunit $a c r-2$, is enriched in motor neurons of the ventral nerve cord (Hallam et al. 2000; Cinar et al. 2005; Jospin et al. 2009). To determine which ventral cord motor neurons express acr-2, we examined transgenic strains that expressed GFP (Chalfie et al. 1994) under the control of acr-2 regulatory sequences. Expression of Pacr-2::GFP was limited to the nervous 
system and largely restricted to neurons located in the ventral nerve cord. Expression of Pacr-2::GFP did not overlap with expression of a GABAergic mCherry reporter (Punc-47::mCherry), indicating that expression of acr-2 was limited to cholinergic motor neurons (DA, VA, DB, VB) in the ventral nerve cord of adult animals (Fig. 1A). To determine the subcellular localization of ACR-2, we generated transgenic strains that expressed a fulllength ACR-2::GFP fusion protein in which GFP was inserted in frame in the intracellular loop region located between transmembrane domains three and 4 (Fig. S1, available at www.jneurosci.org as supplemental material). Expression of the GFP reporter construct could be observed at all larval stages and in the adult. We noted the onset of expression in late embryogenesis by the threefold stage $(\sim 550 \mathrm{~min}$ after fertilization). In first larval stage (L1) animals, when DA and DB motor neurons are the sole excitatory motor neurons present, ACR-2 expression was clearly visible in ventral nerve cord processes. DA and DB motor neuron dendrites receive synaptic input in the ventral cord, and these neurons extend commissural axons to the dorsal cord where they form neuromuscular synapses with the dorsal musculature. In adult animals, we found that the fusion protein was diffusely localized to neuronal processes of the dorsal and ventral nerve cords. Our analysis suggests that ACR-2 is diffusely localized with enriched expression in the dendritic compartment of cholinergic motor neurons.

The locomotory control interneurons provide synaptic input to the excitatory motor neurons; however, the role of acetylcholine $(\mathrm{ACh})$ in this signaling remains unclear. To evaluate whether the locomotory control interneurons are cholinergic, we examined transgenic strains that coexpressed GFP under control of regulatory elements for the gene encoding the ACh vesicular transporter (Punc-17::GFP) together with the red fluorescent protein mCherry expressed under the control of the regulatory elements for the $n m r-1$ gene (Pnmr-1::mCherry) (Figure S2, available at www.jneurosci.org as supplemental material). $n m r-1$ is expressed in the AVA, AVD, AVE , and PVC locomotory control interneurons, as well as the RIM and AVG neurons (Brockie et al. 2001). We noted no overlap in the pattern of the red and green fluorescent signals with the possible exception of the interneuron AVE, indicating that these two reporters labeled almost completely independent cell populations. These data are consistent with the idea that the locomotory control interneurons are not primarily cholinergic. The enriched expression of ACR-2 in the dendritic compartment of motor neurons may reflect the involvement of ACR-2 receptor complexes at synapses between AVE and cholinergic motor neurons; however, the lack of Punc-17::GFP expression in a majority of locomotory control interneurons and the diffuse distribution of ACR-2 are inconsistent with an exclusive role at synapses.
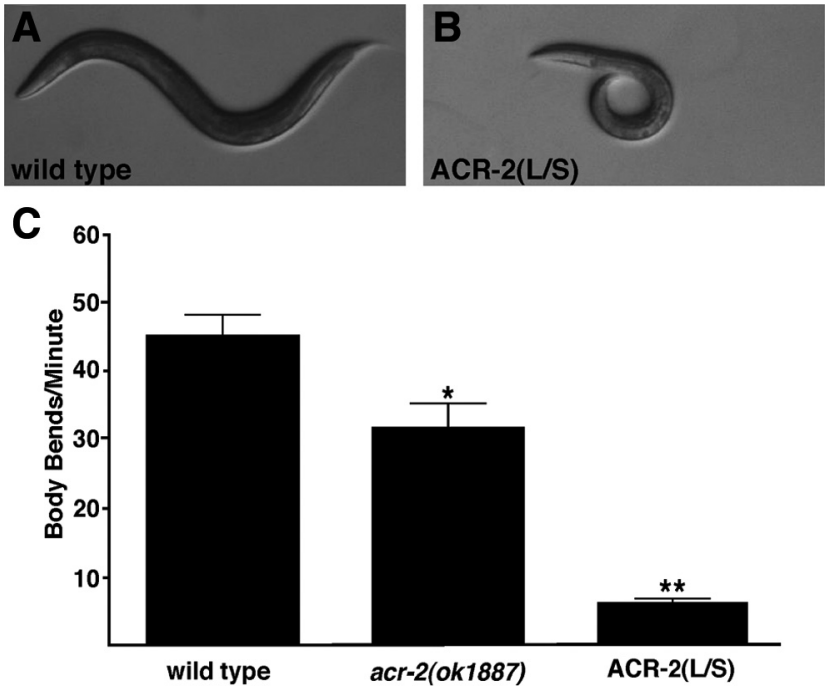

Figure 2. Transgenic animals expressing the dominant $A C R-2(L / S)$ transgene are severely uncoordinated. $\boldsymbol{A}, \boldsymbol{B}$, Still image of a wild-type animal $(\boldsymbol{A})$ and a transgenic animal expressing the $A C R-2(L / S)$ transgene $(\boldsymbol{B})$. Note the coiled posture and reduced size that occurs as a result of ACR-2(L/S) expression. C, Quantification of movement on a food-free agar plate. Average number of body bends per minute for wild type, acr-2(ok1887) mutants, and transgenic animals expressing full-length $A C R-2(L / S)$ (uf/s25) counted over a 5 min period are shown. Data represent mean \pm SEM. of at least 10 trials; ${ }^{*} p<0.02 ;{ }^{* *} p<0.0001$. 

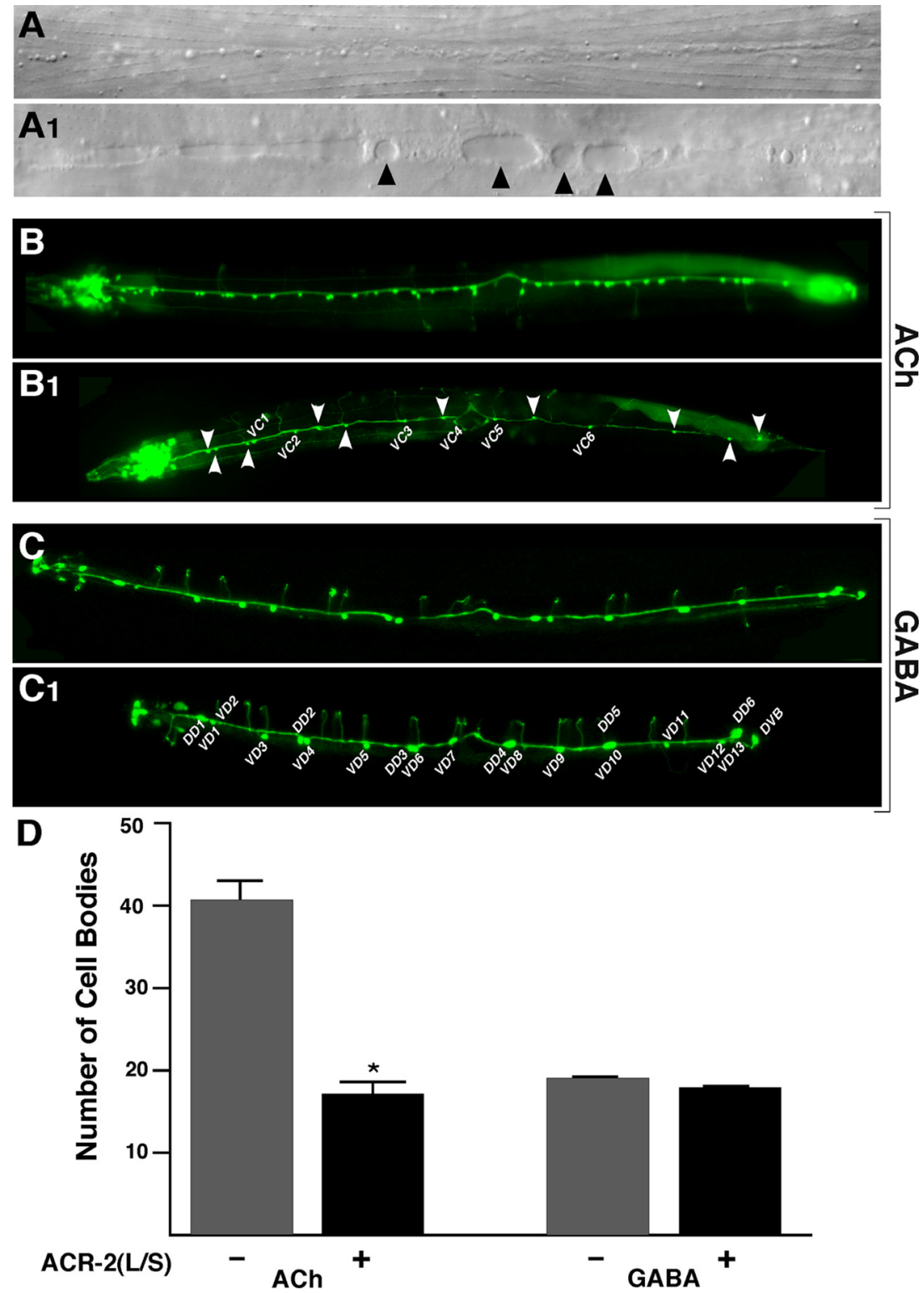

Figure 3. Transgenic expression of $A C R-2(L / S)$ leads to a loss of cholinergic motor neurons. $A, A 1, D I C$ images of an adult wild type animal $(\boldsymbol{A})$ and an adult transgenic animal expressing $A C R-2(L / S)(\boldsymbol{A} 1)$. Triangles denote lesions observed along the ventral nerve cord of transgenic animals expressing ACR-2(L/S). Images show a region directly posterior of the vulva and are oriented with the ventral surface facing up and the anterior of the animal to the left. $\boldsymbol{B}, \boldsymbol{B}$, Wide-field epifluorescent images of a transgenic animal expressing the cholinergic neuron marker Punc-17::GFP (vs/s48) (B) and a transgenic animal coexpressing ACR-2(L/S) with Punc-17::GFP (B1). The few Punc-17::GFP-labeled motor neurons that remain in transgenic ACR-2(L/S) animals include the six VCS (indicated) and a more variable group of $\sim 10-12$ neurons (arrowheads). C, C1, Wide-field epifluorescent images of a transgenic animal expressing Punc-47::mCherry $(C)$ and a transgenic animal coexpressing Punc-47::mCherry with $A C R-2(L / S)(C 1)$. The full complement of Punc-47::mCherry-labeled motor neurons remains in transgenic ACR-2(L/S) animals and is indicated. D, Quantification of the total number of motor neurons in wild-type (gray) and ACR-2(L/S) animals (black); ${ }^{*} p<0.01$. For all images, animals are positioned with the head on the left side of the image.

\section{acr-2 mutants have motor deficits}

The cholinergic motor neurons in the ventral nerve cord make synaptic contacts onto the body wall musculature that drives nematode locomotion. To evaluate the contribution of ACR-2 to cholinergic motor neuron excitability and motor output, we obtained a strain carrying a deletion mutation (ok1887) in the acr-2 genomic locus. The acr-2(ok1887) eliminates $\sim 2.8 \mathrm{~kb}$ of chromosomal DNA, including the transcriptional start, and is likely to be a null. Animals homozygous for the ok1887 allele are healthy and viable. acr-2(ok1887) mutants are not obviously uncoordinated, though closer inspection revealed a modest decrease in locomotion rate (Fig. $1 B$ ). Expression of the full-length ACR-2::GFP fusion protein in $a c r-2(o k 1887)$ mutants was sufficient to restore normal movement.

The acetylcholinesterase inhibitor aldicarb has proven to be a useful tool for detecting alterations in neurotransmitter release from cholinergic motor neurons. To test whether ACR-2 receptor complexes may be important for regulating activity of the cholinergic motor neurons, we examined whether acr-2 mutant worms exhibit altered sensitivity to the paralyzing effects of aldicarb. acr-2 mutant animals were slightly resistant to paralysis by aldicarb, and this effect was normalized by expression of ACR-2::GFP (Fig. 1C). These data are consistent with the notion that ACR-2 plays a role in modulating the activity of cholinergic motor neurons but suggest that ACR-2 is not absolutely required for motor neuron depolarization.

\section{Introducing a dominant mutation in} ACR-2 leads to profound motor deficits The second transmembrane domains of Cys-loop family ligand-gated ion channel subunits are well known to line the ion channel pore and play a critical role in channel gating. In particular, a highly conserved nonpolar residue (typically leucine) in the $\mathrm{M} 2$ region has been shown to have profound effects on receptor activation properties (Fig. S3, available at www.jneurosci.org as supplemental material). Substitution of a polar amino acid (e.g., serine) for the leucine at this position produces a gain-of-function effect, resulting in increased receptor activation and very slow inactivation (Revah et al., 1991; Labarca et al. 1995).

We engineered the homologous leucine-to-serine point mutation into the sequence encoding the M2 $9^{\prime}$ position of an $a c r-2$ rescuing construct to generate ACR-2(L/S) (Fig. S3, available at www. jneurosci.org as supplemental material). Transgenic animals expressing an integrated ACR-2(L/S) array (ufIs25) were used for all subsequent analyses. These animals are viable and have roughly normal brood sizes; however, adult animals are smaller than their wild-type counterparts (Fig. 2). Moreover, we noted obvious locomotory defects in transgenic ACR-2(L/S) animals (Fig. 2C). These defects were present in all larval stages as well as adult animals. Transgenic ACR-2(L/S) animals generated almost tenfold fewer body bends than the wild type and failed to propagate the sinusoidal wave that is typical of nematode movement, although animals remained capable of head foraging movements. The effects of ACR-2(L/S) were dominant, consistent with the notion that the phenotypes arose as a consequence of expression 

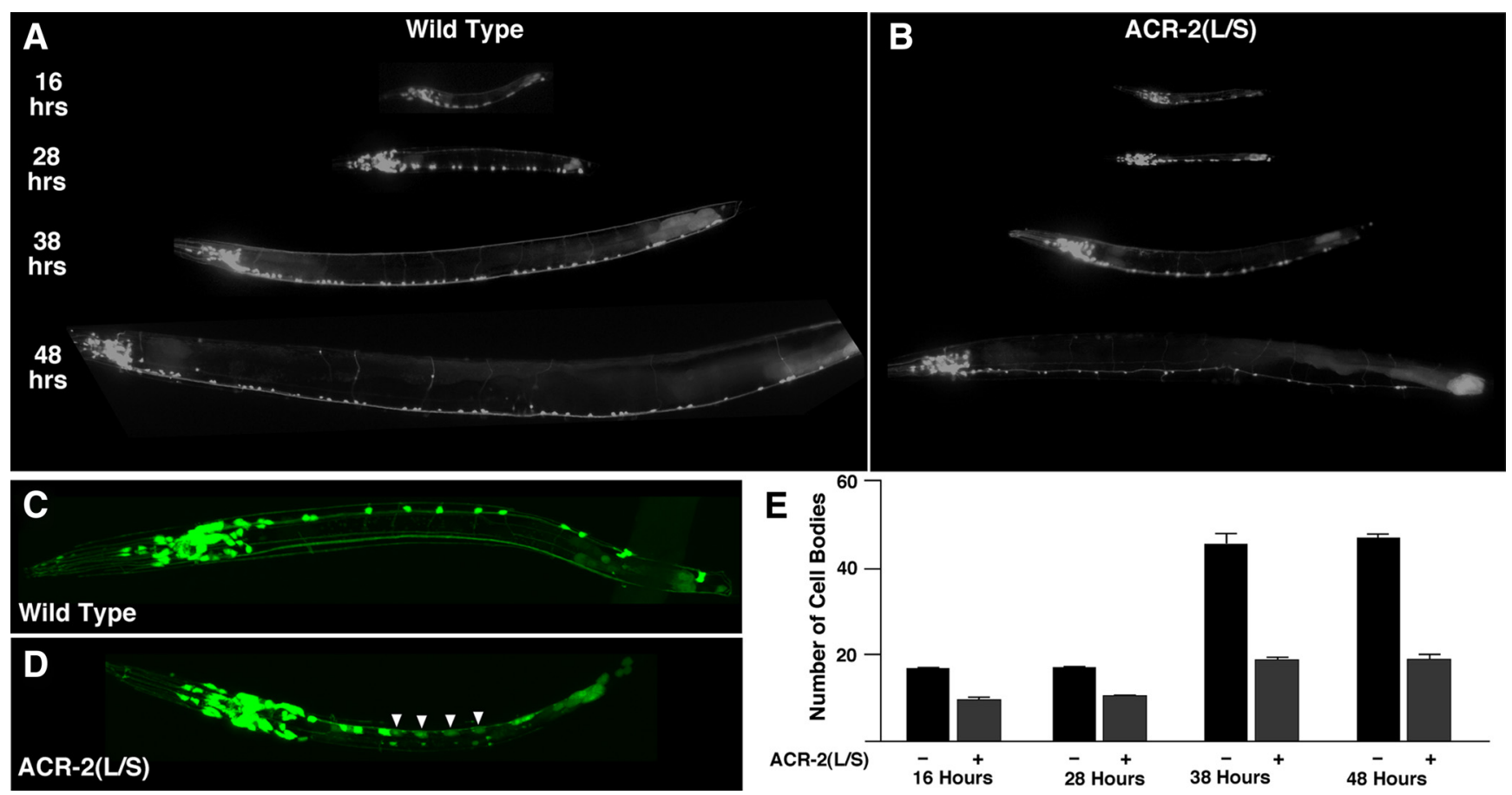

Figure 4. $\quad A C R-2(L / S)$-induced motor neuron cell death is initiated before hatch. $A, B$, Wide-field epifluorescent images of wild-type $(\boldsymbol{A})$ and transgenic $A C R-2(L / S)(B)$ animals expressing Punc-17::GFP imaged 16, 28, 38, and $48 \mathrm{~h}$ after bleach synchronization of embryos. $\boldsymbol{C}, \boldsymbol{D}$, Confocal images of first larval stage wild-type $(\boldsymbol{C})$ and transgenic $A C R-2(\mathrm{~L} / \mathrm{S})(\boldsymbol{D})$ animals expressing Punc-17::GFP. Swollen or dying neuronal cell bodies are indicated (arrowheads). $\boldsymbol{E}$, Quantification of the average number of cell bodies at the time points indicated for wild type (black bars) and transgenic ACR-2(L/S) animals (gray bars). Bars represent the mean \pm SEM for $5-8$ animals at each time point.

of a gain-of-function receptor. Our results suggest that motor output to head muscles is unaffected, while control of body wall musculature is dramatically impaired in these animals.

\section{ACR-2(L/S)-induced motor neuron degeneration}

Examination of the ventral nerve cord region of transgenic ACR$2(\mathrm{~L} / \mathrm{S})$ animals by differential interference contrast (DIC) microscopy showed that a subset of the ventral nerve cord neurons that normally express acr-2 swelled beyond their normal diameter and eventually disappeared, presumably as a result of cell death (Figs. 3, 4). These results suggest that enhanced cholinergic signaling mediated by receptors incorporating ACR-2(L/S) leads to motor neuron toxicity. To characterize this in more detail, we examined the effects of ACR-2(L/S) expression in strains carrying fluorescent reporters that label populations of cholinergic neurons. We observed only dim Pacr-2::GFP fluorescence in the ventral nerve cord of ACR-2(L/S) animals, suggesting that many of the neurons labeled by this reporter were lost (data not shown). To evaluate the specificity of this effect for neurons that expressed acr-2, we examined a Punc-17::GFP reporter that is expressed in all cholinergic neurons (Fig. 3) (Chase et al. 2004). While ACR$2(\mathrm{~L} / \mathrm{S})$ expression did not produce obvious differences in the number of head neurons labeled by $\mathrm{P}$ unc-17::GFP, we observed a dramatic decrease in the number of ventral nerve cord motor neuron cell bodies; yet, several motor neuron cell bodies remained present. The surviving neurons included the six VC motor neurons that do not normally express acr-2 and a more variable group of 10-12 additional excitatory motor neuron cell bodies (Figs. 3; Fig. S4, available at www.jneurosci.org as supplemental material). Based on the position and number of cell bodies and commissural processes, the additional surviving neurons included both DA and DB motor neurons that normally express acr-2, as well as AS motor neurons that do not. Similar to our observations for ACR-2(L/S)-induced paralysis, the effects of ACR-2(L/S) on motor neurons were dominant. To evaluate the effects of ACR-2(L/S) on GABA motor neurons, we coexpressed ACR-2(L/S) together with a mCherry transcriptional reporter that labeled GABA neurons (Punc-47::mCherry) (Fig. 3C,D). We observed that the full complement of GABA neurons was present and morphologically normal. These data suggest that ACR2(L/S) acts cell autonomously to promote degeneration of motor neurons and that specific neurons are differentially susceptible to the effects of ACR-2(L/S) expression.

\section{Motor neuron loss occurs soon after onset of ACR-2(L/S) expression}

As noted above, we observed clear ACR-2::GFP fluorescence in late embryogenesis. We found that threefold embryos coexpressing ACR-2(L/S) with the Pacr-2::GFP transcriptional reporter possessed normal numbers of GFP-positive neurons, suggesting that ACR-2(L/S) toxicity occurred after hatch (Fig. S4, available at www.jneurosci.org as supplemental material). To precisely determine the onset of motor neuron cell death, we imaged transgenic ACR-2(L/S) animals that coexpressed the Punc-17::GFP transcriptional reporter at various time points ranging from newly hatched larvae to adults (Fig. 4). We observed significant motor neuron loss in newly hatched larvae. Roughly $40 \%$ of the 16 cholinergic motor neurons present in L1 animals were lost within $16 \mathrm{~h}$ after hatch. During the transition from the first larval stage to the second larval stage (L2) the number of ventral nerve cord motor neurons increases substantially, with the addition of $>50$ motor neuron cell bodies (Sulston and Horvitz, 1977). In transgenic ACR-2(L/S) animals we observed only a slight increase in the number of cell bodies labeled by Punc-17::GFP over the course of development. Even by the time transgenic ACR-2(L/S) animals had clearly reached adulthood, the number of 
Table 1. Several $n A C h R$ subunits are required for $A C R-2(L / S)$-induced paralysis

\begin{tabular}{lll}
\hline Gene & ACR-2(L/S) suppression & Description \\
\hline acr-2(ok1887) & - & $\mathrm{nAChR}$ non- $\alpha$ subunit \\
acr-3(ok2049) & - & $\mathrm{nAChR}$ non- $\alpha$ subunit \\
acr-5(ok180) & - & $\mathrm{nAChR} \alpha$ subunit \\
acr-9(ok933) & - & $\mathrm{nAChR}$ non- $\alpha$ subunit \\
acr-12(ok367) & + & $\mathrm{nAChR} \alpha$ subunit \\
acr-14(ok1155) & - & $\mathrm{nAChR} \alpha$ subunit \\
acr-15(ok1214) & - & $\mathrm{nAChR} \alpha$ subunit \\
acr-16(ok789) & - & $\mathrm{nAChR} \alpha$ subunit \\
acr-19(ok967) & - & $\mathrm{nAChR} \alpha$ subunit \\
acr-23(ok2840) & - & $\mathrm{nAChR} \alpha$ subunit \\
unc-63(x37) & + & $\mathrm{nAChR} \alpha$ subunit \\
unc-38(e264) & + & $\mathrm{nAChR} \alpha$ subunit \\
unc-29(x29) & - & $\mathrm{nAChR}$ non- $\alpha$ subunit \\
unc-50(e306) & + & Golgi integral membrane protein \\
unc-74(e883) & + & Function unknown \\
\hline
\end{tabular}

Punc-17::GFP labeled motor neuron cell bodies was roughly comparable to that of a wild-type L1 animal. The VC motor neurons do not express acr-2 and are clearly present in transgenic ACR-2(L/S) animals (Fig. 3; Fig. S5, available at www.jneurosci. org as supplemental material). Therefore, the small developmental increase in the number of motor neuron cell bodies that we observe in transgenic ACR-2(L/S) animals likely represents the postembryonic addition of $\mathrm{VC}$ neurons. These results suggest that the other classes of motor neurons that are born postembryonically and normally express acr-2 (e.g., VA, VB) are almost completely absent in adult transgenic ACR-2(L/S) animals.

\section{Mutations that suppress paralysis define the subunits of a neuronal nAChR}

To identify genes required for the toxic effects of transgenic ACR$2(\mathrm{~L} / \mathrm{S})$ expression, we conducted a forward genetic screen for suppressors of ACR-2(L/S)-induced paralysis. We screened the F2 progeny of mutagenized hermaphrodites that expressed ACR$2(\mathrm{~L} / \mathrm{S})$ and selected animals that exhibited improved movement. A close examination of the mutants isolated from the screen showed that two phenotypic classes were easily distinguishable. One class of animals phenocopied strains that lack a well characterized heteromeric $\mathrm{nAChR}$ that mediates excitatory signaling at the neuromuscular junction (NMJ) and is a principal target of the antihelminthic drug levamisole (L-AChR). We found that members of this class were strongly levamisole-resistant, and we isolated alleles of the levamisole resistance genes unc-38, unc-63, unc-74, and unc-50 from these animals (supplemental Table S1, available at www.jneurosci.org as supplemental material). We also crossed available strains carrying single loss-of-function mutations in known levamisole resistance genes with transgenic ACR-2(L/S) animals (Table 1). Consistent with the results from our forward genetic approach, loss-of-function mutations in either $u n c-38, u n c-63$, unc-74, or unc-50 were sufficient to suppress ACR-2(L/S) toxicity and restore movement (Fig. $5 A$ ). Interestingly, we also found that $u n c-29$, a non- $\alpha$ subunit required for L-AChR function, was not required for ACR-2(L/S)-induced paralysis. Likewise, acr-16, an essential subunit of homomeric nAChRs at the NMJ, was not required for ACR-2(L/S)-induced paralysis. unc-38 and unc-63 encode nAChR $\alpha$ subunits that are required for L-AChR function at the NMJ but are also expressed in the nervous system (Fleming et al. 1997; Culetto et al. 2004; Eimer et al. 2007). unc-50 and unc-74 encode genes previously implicated in L-AChR maturation and are broadly expressed in

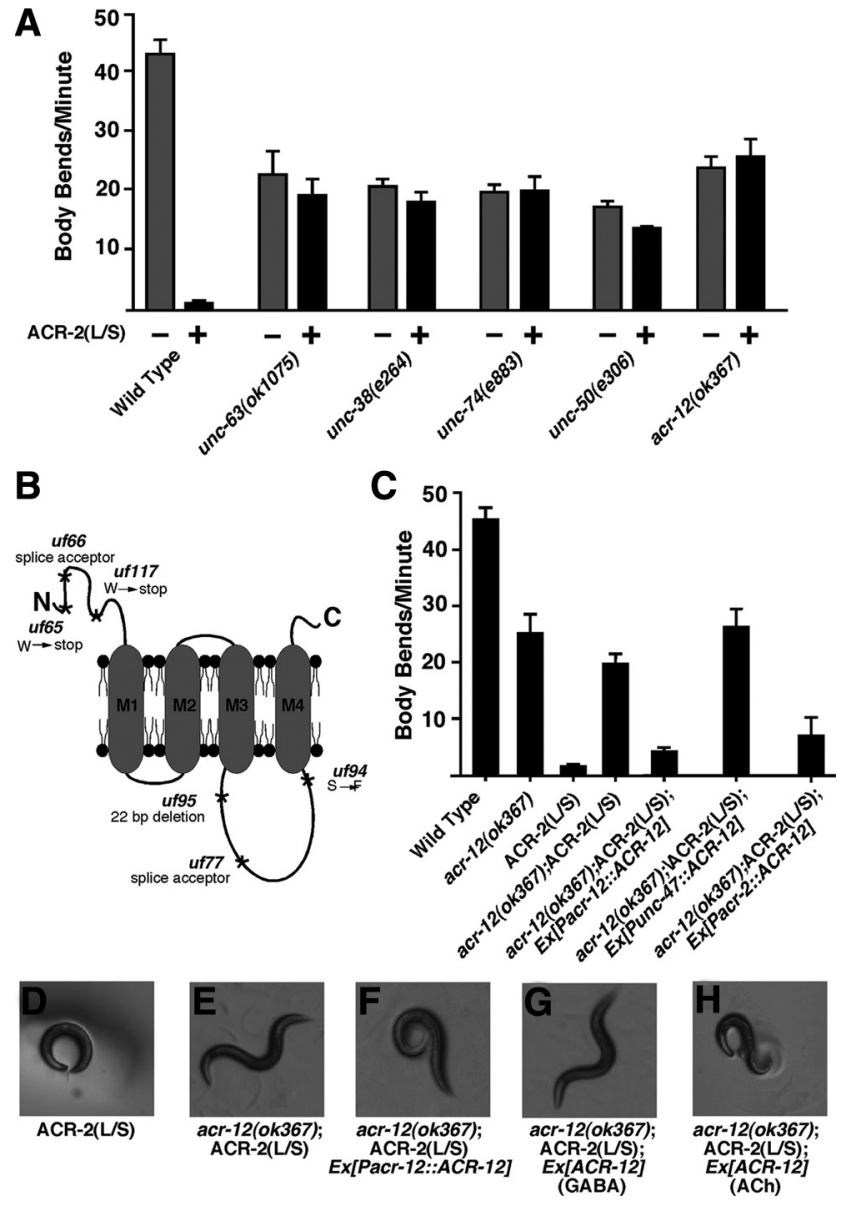

Figure 5. Mutations in nicotinic acetylcholine receptor subunits suppress $A C R-2(L / S)$ induced paralysis. $\boldsymbol{A}$, Quantification of the average number of body bends per minute for wildtype animals, acr-12(ok367), unc-63(ok1075), unc-38(e264), unc-74(e883), and unc-50(e306) mutants in the absence (gray bars) or presence (black bars) of the ACR-2(L/S) transgene. Animals were placed on a food-free agar plate, and the average number of body bends per minute was quantified over a 5 min period. Data represent the mean $\pm S E M$. of at least 10 animals for each genotype. $B$, Schematic of the membrane topology of ACR-12 with approximate location, allele names, and molecular nature of loss-of-function mutations that suppress $A C R-2(L / S)$ toxicity indicated. C, Quantification of the average number of body bends per minute for the following genotypes: wild type, acr-12(ok367), transgenic ACR-2(L/S), acr-12 mutants expressing $A C R-2(\mathrm{~L} / \mathrm{S})$, acr-12 mutants expressing $A C R-2(\mathrm{~L} / \mathrm{S})$ together with an extrachromosomal array containing Punc-47::ACR-12, and acr-12 mutants expressing ACR-2(L/S) together with an extrachromosomal array containing the Pacr-2::ACR-12 cDNA. Data represent the mean \pm SEM. for 5-10 animals. $\boldsymbol{D}-\boldsymbol{H}$, Still images of adult animals on NGM plates without food for the genotypes indicated. "GABA" and " $A C h$ " refer to specific expression of the acr- 12 CDNA in GABAergic or cholinergic neurons using the unc -47 or acr-2 promoters, respectively.

muscles and neurons. Our analysis suggests that each of these gene products may contribute in a cooperative fashion to the generation of functional ACR-2(L/S) receptors and subsequent toxicity.

A smaller number of animals isolated from the screen exhibited uncoordinated movement with deep body bends and showed normal sensitivity to the paralyzing effects of levamisole. We determined that the suppressor mutations in this second phenotypic class represented one complementation group and were $\mathrm{X}$ linked. Using single-nucleotide polymorphism mapping, we mapped one allele to the right of +8 on the $\mathrm{X}$ chromosome. The nAChR subunit gene acr-12 is located in this genomic region. Sequence analysis revealed four nonsense mutations and two missense mutations in the acr-12 coding sequence among our second class of suppressors (Fig. $5 B$ ). We also found that a dele- 
tion mutation (ok367) in the acr-12 gene suppressed paralysis in transgenic ACR2(L/S) animals and prevented the loss of motor neuron cell bodies. Expression of a full-length $a c r-12$ rescuing construct in acr-12(ok367);ACR-2(L/S) animals restored paralysis, verifying that $a c r-12$ is required (Fig. 5C,F). In contrast, we found that several other nAChR subunits with restricted expression to the nervous system were not required for ACR-2(L/S)induced paralysis (Table 1). acr-12 encodes a nicotinic receptor $\alpha$ subunit that is broadly expressed in the nervous system, including many ventral cord motor neurons, but is not expressed in body wall muscles (Cinar et al. 2005; Gottschalk et al. 2005). acr-12(ok367) mutants have grossly normal movement and show normal sensitivity to the paralyzing effects of levamisole. To test whether acr-12 expression solely in cholinergic motor neurons is sufficient for ACR-2(L/S)-induced toxicity, we specifically restored expression of acr-12 to either ACh or GABA motor neurons of acr-12(ok367) mutants that carried the ACR-2(L/S) transgene (Fig. 5C$\mathrm{H})$. We found that-specific expression of the acr-12 cDNA in cholinergic motor neurons of transgenic acr-12(ok367); ACR-2(L/S) mutants led to ACR-2(L/S) toxicity and paralysis. In contrast, specific expression in GABA neurons had no effect. Our results indicate that acr-12 expression in cholinergic motor neurons is specifically required for ACR-2(L/S)-induced cell death. Furthermore, our results suggest that coassembly of ACR-2(L/S) into a heteromeric receptor complex with UNC-38, UNC-63, and ACR-12 is required to produce toxicity.

\section{ACR-2(L/S)-induced motor neuron}

loss is suppressed in $c n x-1 ;$ crt-1 double mutants

At least two mechanistically distinct types of cell death have been described. Programmed cell death or apoptosis is a form of cell death common in development and tissue homeostasis and occurs by a genetic program that is broadly conserved across metazoans (Danial and Korsmeyer, 2004). Necrosis generally occurs following cellular injury and is often characterized by swelling of the dying cell (Festjens et al. 2006; Golstein and Kroemer, 2007). Our forward genetic screen did not identify genes previously implicated in the execution of either of these forms of cell death. To determine how ACR-2(L/S) expression leads to cell death, we introduced the ACR-2(L/S) transgene into genetic backgrounds deficient for genes essential for either apoptotic cell death or necrotic cell death (Fig. 6). We found that a loss-of-function mutation in proapoptotic ced-3 (Ellis and Horvitz, 1986) or a gain-of-function mutation in anti-apoptotic ced-9 (Hengartner et al. 1992) had no effect on ACR-2(L/S)-induced deaths. Thus, the programmed cell death machinery is not required for ACR-2(L/S)-induced neurodegeneration.

Dysregulation of intracellular calcium levels contributes to cell death under a variety of circumstances, including necrotic cell death (Mattson et al. 2000; Rao et al. 2004; Szydlowska and Tymianski, 2010). Calreticulin/CRT-1 and calnexin/CNX-1 are endoplasmic reticulum (ER) resident proteins that serve dual functions as $\mathrm{Ca}^{2+}$ binding proteins and molecular chaperones that facilitate glycoprotein folding (Ellgaard and Frickel, 2003). In mice, loss of either calnexin or calreticulin produces severe phenotypes: calnexin knock-out mice die within 4 months of birth, while knock-out of calreticulin results in embryonic lethality caused by defects in heart development (Mesaeli et al. 1999; Denzel et al. 2002). In C. elegans, crt- 1 and $c n x-1$ single mutants are viable, and loss-of-function mutation in the $c r t-1$ gene or RNA interference knockdown of $c n x-1$ expression suppresses several cases of ion channel-mediated cell death (Xu et al. 2001). We found that the deletion mutation $c n x-1(o k 2234)$ had no significant effect on ACR-2(L/S)-induced cell death, whereas the deletion mutation $\mathrm{crt}$-1 (ok948) partially suppressed the loss of motor neurons observed in transgenic ACR-2(L/S) animals. Neither of these mutations led to significant locomotory improvement.

As calnexin and calreticulin perform similar cellular functions, we generated a strain carrying loss-of-function mutations in both genes to test whether they may act redundantly in ACR2(L/S)-induced toxicity. cnx-1;crt-1 double mutants were viable although smaller in size than wild-type animals, had grossly nor- 

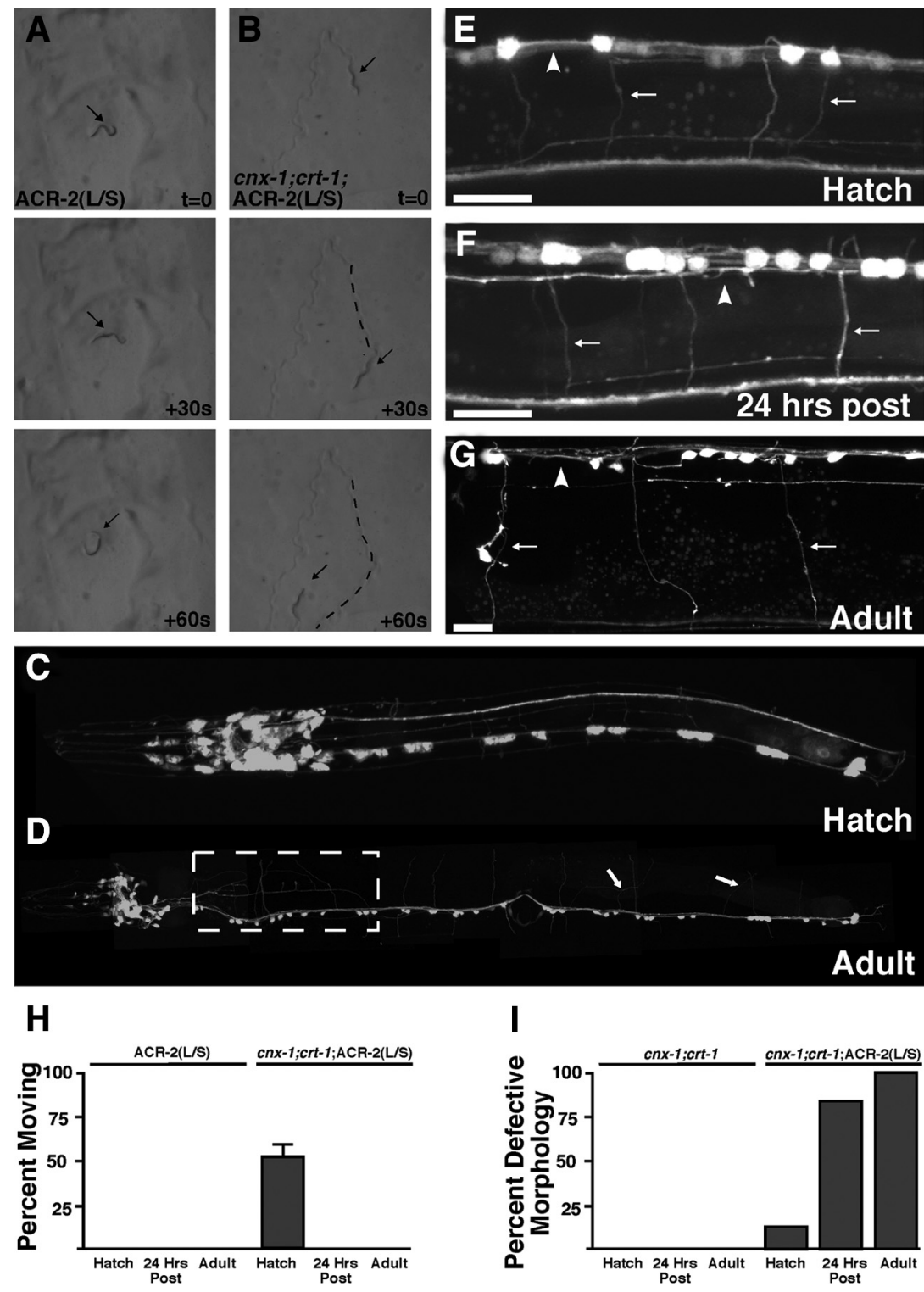

Figure 7. Progressive destabilization of motor neuron processes in $c n x-1 ;(r t-1 ; A C R-2(L / S)$ animals. $A, B$, Frames showing the movement of $\mathrm{L} 1$ transgenic $A C R-2(\mathrm{~L} / \mathrm{S})(\boldsymbol{A})$ or $\mathrm{Cnx}-1 ; \mathrm{crt}-1 ; \mathrm{ACR}-2(\mathrm{~L} / \mathrm{S})(\boldsymbol{B})$ animals $30 \mathrm{~s}(t=0), 60 \mathrm{~s}(+30)$, or $90 \mathrm{~s}(+60)$ after transfer to an agar plate. The black arrow marks the starting positions of the worms in each frame. The transgenic $A C R-2(L / S)$ animal does not move from where it was placed on the plate. The dashed line shows the movement path of the L1 $\mathrm{Cnx}-1$; $\mathrm{Cr}-1$; ACR-2(L/S) animal over the course of $60 \mathrm{~s}$. The additional tracks on the plate show the path of the animal in an $\sim 30$ s period before imaging began. $C, D$, Confocal images of a first larval stage $(\boldsymbol{C})$ or adult $C n x-1 ;(r t-1 ; A C R-2(L / S)$ animals expressing an integrated Punc-17::GFP (D). Images show Z-projections of 15 confocal planes $(0.5 \mu \mathrm{m} / \mathrm{slice})(\boldsymbol{C})$ or 16 confocal planes $(0.5 \mu \mathrm{m} / \mathrm{slice})(\boldsymbol{D})$. Arrows $(\boldsymbol{D})$ indicate positions of commissures. Dashed box $(\boldsymbol{D})$ indicates area with multiple neuronal defects. $\boldsymbol{E}-\boldsymbol{G}$, Confocal images of $\mathrm{Cnx}-1 ; \mathrm{cr}-1 ; \mathrm{ACR}-2(\mathrm{~L} / \mathrm{S})$ animals taken at hatch $(\boldsymbol{E}), 24 \mathrm{~h}$ posthatch $(\boldsymbol{F})$, and adulthood $(\boldsymbol{G})$. In each case, a region immediately posterior of the vulva was imaged and the ventral nerve cord is positioned at the top. Arrows indicate commissural processes; arrowheads indicate the ventral nerve cord. Images show Z-projections of 12 confocal planes $(\boldsymbol{E}), 23$ confocal planes $(\boldsymbol{F})$, or 33 confocal planes $(\boldsymbol{G})(0.5 \mu \mathrm{m} / \mathrm{slice})$. Scale bars represent $10 \mu \mathrm{m}$. $\boldsymbol{H}$, Quantification of percentage of animals moving at hatch in ACR-2(L/S) and cnx-1;crt-1;ACR-2(L/S) animals. Data represent the mean number of animals \pm SEM making more than two consecutive body bends during a 3 min period. I, Quantification of the percentage of $c n x-1 ;$; rrt-1 and cnx-1; $r r t-1 ; A C R-2$ (L/S) animals with defective neuronal process morphology. Observed defects include defasciculation of the ventral nerve cord, wandering commissural processes, or ectopic branching.

mal movement, and did not show obvious defects in nervous system connectivity. While ACR-2(L/S) expression in wild-type animals or $c n x-1$ and $c r t-1$ single mutants caused paralysis across all developmental stages, we found that first larval stage $c n x-1$; crt-1 double mutants expressing ACR-2(L/S) were often capable of grossly normal locomotion (Fig. $7 A, B, H$ ). We also observed

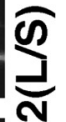

Hatch

that the full complement of 16 cholinergic motor neuron cell bodies was present in L1 cnx-1;crt-1;ACR-2(L/S) animals, and we did not detect obvious defects in the connectivity of the cholinergic motor neurons (Fig. 7C). These results indicate that embryonic born motor neurons developed normally and made appropriate synaptic contacts onto their partner muscle cells, suggesting that the combined loss of $c r t-1$ and $c n x-1$ is strongly neuroprotective against ACR-2(L/S) toxicity in L1 animals. We observed that adult $c n x-1 ; c r t-1$ double mutants expressing ACR-2(L/S) also possessed normal numbers of cholinergic motor neuron cell bodies, providing additional evidence that the presence of either calnexin or calreticulin is required for the cellular events that lead to ACR-2(L/S)induced cell deaths (Figs. 6F, G, 7D). However, larvae that had progressed beyond L1 and adult $c n x-1 ; c r t-1 ; \mathrm{ACR}-2(\mathrm{~L} / \mathrm{S})$ animals were unable to propagate sinusoidal body bends and move effectively. This observation suggested that ACR-2(L/S) expression in $c n x-1 ; c r t-1$ double mutants led to a progressive disruption of motor function even when motor neuron death was attenuated.

To determine whether altered motor neuron connectivity may underlie the paralysis of adult cnx-1;crt-1;ACR-2(L/S) animals, we made a close examination of the cholinergic motor neuron processes (Fig. $7 E-G, I$ ). We found that defects in the motor neuron processes of control cnx-1;crt-1 double mutants occurred only rarely (Fig. S6, available at www.jneurosci. org as supplemental material), and these animals exhibited grossly normal movement across all stages of development. In cnx-1;crt-1 double mutants that expressed ACR-2(L/S), we observed defasciculation of the ventral nerve cord neuronal processes (in $96 \%$ of animals scored; $n=30$ ), as well as defects in the morphology of commissural axons (in 75\% of axons) (Fig. 7). We often observed several classes of defects within individual animals and, in some instances, individual commissural axons contained multiple defects. The defects were of several types. First, we observed abnormal axon branches that often terminated in growth conelike structures (54\% of animals). Second, we observed ectopic sprouting with no clear single axonal process present $(71 \%$ of animals). Finally, we observed axons with abnormal trajectories and wandering growth ( $83 \%$ of animals). These results suggest that the muscle targets of cholinergic motor neuron processes are not appropriately innervated in adult animals. We observed that the frequency of these defects increased dramatically after the first larval stage (Fig. 7I), suggesting that a progressive deficiency 

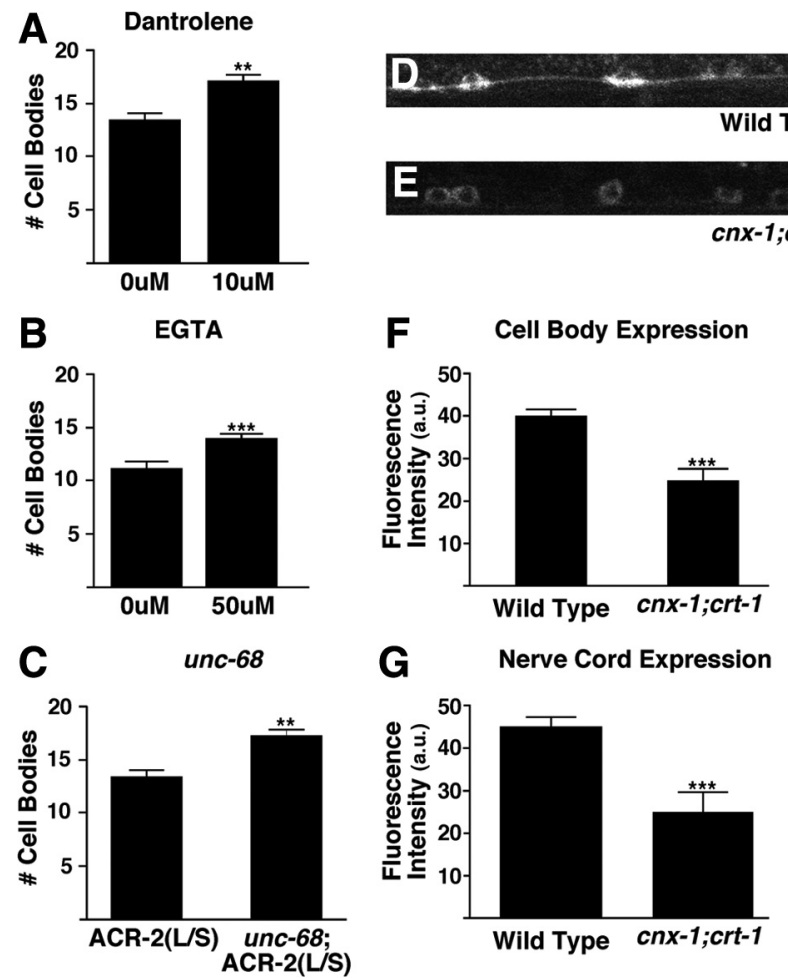

G
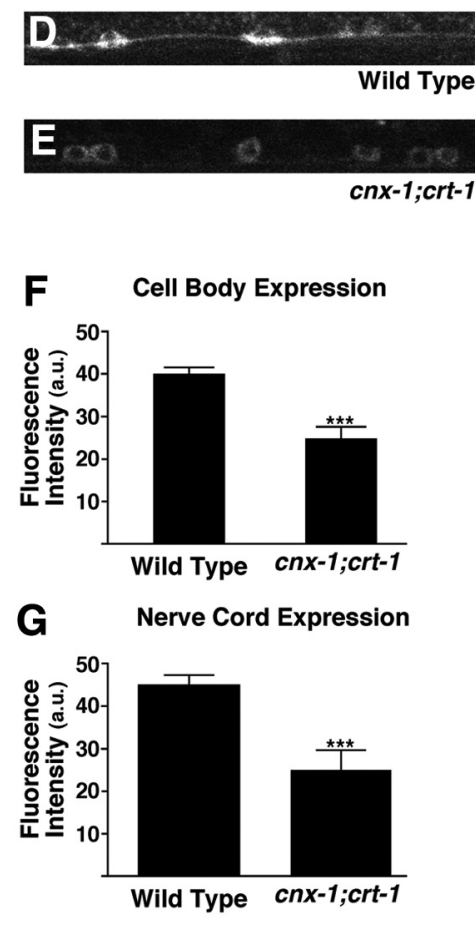

Figure 8. Perturbation of intracellular calcium and reduced ACR-2::GFP levels in cnx-1;crt-1 double mutants suggest dual mechanisms for cell death suppression. $\boldsymbol{A}-\boldsymbol{C}$, Quantification of the average number of Punc-17::GFP-labeled cell bodies present in the ventral nerve cord in adult animals treated with dantrolene $(\boldsymbol{A})$, L1 animals treated with EGTA $(\boldsymbol{B})$, and adult unc-68(e540) mutant animals (C). Data represent the mean \pm SEM. for at least eight animals. ${ }^{* *} p<0.01$, ${ }^{* * *} p<0.01$, compared to untreated ACR-2(L/S) animals. $\boldsymbol{D}, \boldsymbol{E}$, Confocal images of adult wild type (D) or cnx-1; $r$ rt- 7 (E) animals expressing ACR-2::GFP. Images are taken immediately posterior to the vulva and show Z-projections of seven confocal planes ( $0.5 \mu \mathrm{m} / \mathrm{slice}) . \boldsymbol{F}, \boldsymbol{G}$, Quantification of fluorescence levels in cell bodies $(\boldsymbol{F})$ and ventral nerve cord processes $(\boldsymbol{G})$ of wild-type and ACR-2(L/S) animals transgenically expressing ACR-2::GFP. Data represent the mean \pm SEM. for at least 10 animals. ${ }^{* *} p<0.01$, compared to ACR-2(L/S) animals.

in the stabilization or maintenance of appropriate neuromuscular connectivity underlies the paralysis we observed in mature animals.

To better understand the mechanisms underlying the suppression of ACR-2(L/S)-mediated cell death in $c n x-1 ; c r t-1$ animals, we directly evaluated the role of intracellular calcium. We found that culturing transgenic ACR-2(L/S) animals in the presence of dantrolene, an inhibitor of ER calcium release, or the calcium chelator EGTA (Fig. $8 A, B$ ) led to a modest but significant increase in the number of surviving motor neuron cell bodies. Similarly, we observed reduced ACR-2(L/S) toxicity in unc-68 mutants lacking functional ryanodine receptors (Fig. $8 C$ ). These results provide evidence that intracellular calcium signaling contributes to cell death in ACR-2(L/S) animals and support the idea that altered intracellular calcium in $c n x-1 ; c r t-1$ double mutants may likewise contribute to the neuroprotection we observed. To test whether altered expression of ACR-2(L/S) in cnx-1;crt-1 double mutants may also be a contributing factor, we measured levels of ACR-2::GFP fluorescence. We observed an approximately twofold decrease in ACR-2::GFP fluorescence in both the cell bodies and ventral nerve cord of $c n x-1 ; c r t-1$ double mutant animals compared to wild-type animals (Fig. $8 D-G$ ). This result suggests that a decrease in the levels of ACR-2(L/S) in cnx-1;crt-1 animals also contributes to the neuroprotection we observe.

\section{Discussion}

Our analysis of ACR-2-containing nicotinic receptors in $C$. elegans neurons has revealed common features between the function of these receptors in the C. elegans nervous system and roles for heteromeric nAChRs in the vertebrate brain (Dani and Bertrand, 2007). First, heteromeric nAChRs in the mammalian brain are not primarily concentrated at postsynaptic sites; instead, they are more variably localized to presynaptic, preterminal, and nonsynaptic sites. Similarly, we find that ACR-2-containing nAChRs appear diffusely localized to the processes of excitatory motor neurons, suggesting that these receptors may function at extrasynaptic sites. Second, heteromeric brain nAChRs primarily function to modulate neurotransmitter release and neuronal excitability. Our studies of acr-2 loss-of-function mutants indicate that heteromeric nAChRs containing ACR-2 modulate the excitability of cholinergic motor neurons but are not absolutely required for motor neuron depolarization or ACh release at neuromuscular synapses. Third, mouse studies have shown that knock-in expression of a heteromeric brain nAChR subunit bearing a L/S pore modification homologous to the one we describe here causes dramatic neuron loss and perinatal lethality (Labarca et al. 2001). Likewise, transgenic expression of ACR-2(L/S) leads to cell-autonomous neurodegeneration.

Importantly, our transgenic approach also enabled us to identify genes required for ACR-2(L/S) toxicity. Mutations that suppressed both the paralysis and neurodegeneration caused by ACR-2(L/S) expression defined the constituent subunits of a putative multimeric ACR-2 receptor complex as well as genes required for receptor trafficking and assembly. Additionally, a single gene mutation in crt-1, previously shown to suppress other forms of ion channel-mediated cell death in C. elegans, partially suppressed ACR-2(L/S) toxicity. We found that the loss of motor neurons caused by ACR-2(L/S) expression was completely suppressed in adult $c n x-1 ; c r t-1$ double mutants; yet, these animals remained paralyzed. Interestingly, suppression of ACR-2(L/S)induced cell death uncovered a secondary consequence of ACR2(L/S) expression: the accumulation of morphological defects in the processes of surviving motor neurons. These axonal defects resemble outgrowth errors typically associated with secondary regrowth of axons (Knobel et al. 2001; Hammarlund et al. 2007). Therefore, the severe morphological defects we observed in adult animals may reflect inappropriate regrowth subsequent to destabilization. We propose that the necrotic-like cell death and destabilization of neuronal processes observed in our studies may represent genetically separable events and suggest that our transgenic approach may afford a powerful system to tease apart the molecular pathways that differentially contribute to these two processes.

\section{ACR-2 is part of a heteromeric $\mathrm{nAChR}$ in cholinergic motor neurons}

We have demonstrated that acr-2 shows restricted expression to cholinergic motor neurons of the ventral nerve cord and appears diffusely localized in neuronal processes. These results suggest that the ACR-2 receptor complex may modulate motor neuron excitability by mediating signaling at extrasynaptic sites. Consistent with this notion, acr-2 loss-of-function mutants are not grossly uncoordinated and show only modest resistance to the paralyzing effects of the ACh esterase inhibitor aldicarb. Aldicarb-induced paralysis arises as a consequence of the prolonged action of ACh in the synaptic cleft; our analysis suggests that ACh release from motor neurons is decreased in acr-2 mutants. Another recent study reached a similar conclusion based on 
electrophysiological analysis of acr-2 loss-of-function mutants (Jospin et al. 2009). We also show that the locomotory control interneurons (with the possible exception of AVE)—-the major source of synaptic inputs to excitatory motor neurons- do not express a reporter that labels cholinergic neurons, suggesting these neurons are unlikely to be cholinergic. Therefore, what is the source of ACh for activation of ACR-2 receptor complexes? The presynaptic ACh release sites of en passant neuromuscular synapses are highly intermingled and densely packed because of the intercalation of neuronal processes in the nerve cord. Thus, one possibility is that these receptors are activated by spillover of ACh from release sites at nearby neuromuscular synapses.

Our genetic analysis showed that mutations in three genes encoding AChR subunits can suppress the neurotoxic effects associated with expression of pore-modified ACR-2(L/S) receptors. unc-38 and unc-63 are highly expressed in ventral cord motor neurons and also contribute to a heteromeric receptor complex that mediates excitatory neurotransmission at the NMJ (Fleming et al. 1997; Culetto et al. 2004). acr-12 is broadly expressed in the nervous system but is not expressed in body wall muscles (Cinar et al. 2005; Gottschalk et al. 2005). Our data are consistent with the notion that UNC-38, UNC-63, and ACR-12 coassemble with the ACR-2 subunit [either native ACR-2 or transgenic ACR-2(L/S)] to form heteromeric nAChRs in cholinergic motor neurons (Jospin et al. 2009). Loss-of-function mutations in any of these genes impair assembly or function of ACR-2 receptor complexes in cholinergic motor neurons and suppress ACR-2(L/S)-induced cell death. Several pieces of evidence support this idea. First, mutations in $u n c-29$ and acr-16- genes that contribute to nAChRs at the NMJ and are essential for normal excitatory neurotransmission at neuromuscular synapses (Richmond and Jorgensen, 1999; Francis et al. 2005; Touroutine et al. 2005) — do not suppress ACR-2(L/S) neurotoxicity, indicating that reduced excitatory neuromuscular signaling alone is insufficient to suppress ACR-2(L/S)-induced toxicity. Second, specific expression of acr-12 in the cholinergic motor neurons of transgenic acr-12 mutants expressing ACR-2(L/S) was sufficient to produce paralysis, whereas specific expression of acr-12 in other neuron classes was without effect. Third, it has recently been shown that coexpression of five subunits-ACR-2, ACR-12, UNC-38, UNC-63, and ACR-3was required for reconstitution of ACR-2 receptor complexes in a heterologous system (Jospin et al. 2009).

\section{Pore-modified ACR-2(L/S) receptors cause ion channel-mediated neurotoxicity}

We have shown that expression of the ACR-2(L/S) transgene leads to degeneration of the cholinergic motor neurons and paralysis, reinforcing the importance of these neurons in generating sinusoidal movement. The GABA motor neurons develop normally even in the absence of ACh motor neurons, their major source of synaptic input, indicating that the toxic effects of ACR$2(\mathrm{~L} / \mathrm{S})$ expression are cell autonomous. We found that mutations in genes that are essential for the formation of functional ACR-2 heteromeric receptors suppress this effect, consistent with the idea that excessive receptor activity leads to neurodegeneration. Our results suggest that the level of receptor activity is a critical determinant in the progression toward necrotic cell death. Consistent with this idea, a less severe gain-of-function acr-2 allele leads to cellular hyperexcitability without obvious loss of motor neurons (Jospin et al. 2009). Interestingly, mouse studies using knock-in expression of similarly pore-modified heteromeric $\mathrm{nAChR}$ subunits have reported qualitatively similar degeneration as a consequence of excess receptor activation (Orr-Urtreger et al.
2000; Labarca et al. 2001; Orb et al. 2004). Knock-out of Lynx1, an endogenous negative regulator of $\mathrm{nAChR}$ function in the mouse brain, also leads to a similar form of vacuolating degeneration that is exacerbated by nicotine (Miwa et al. 2006).

Release of calcium from internal stores plays a major a role in many forms of cell death, including some forms of ion channelmediated toxicity. Pharmacological or genetic manipulation of intracellular calcium levels led to a modest suppression of ACR$2(\mathrm{~L} / \mathrm{S})$-induced toxicity, providing evidence that calcium plays an important role. However, ACR-2::GFP fluorescence was decreased substantially in $c n x-1 ; c r t-1$ double mutants, suggesting that a reduction in protein levels of the toxic transgene also contributes to suppression of cell death. Similar to the case for ACR$2(\mathrm{~L} / \mathrm{S})$ expression, cell death because of a gain-of-function mutation in another C. elegans nAChR subunit, DEG-3, is not suppressed by a single gene mutation in crt-1 (Treinin and Chalfie, 1995; Xu et al. 2001; Syntichaki et al. 2002). Our findings suggest that a requirement for genes additional to $c r t-1$ may be a common feature of nAChR-mediated neuronal death that is distinct from cell death caused by hyperactive $\mathrm{Na}^{+}$channels such as MEC-4(d).

In mouse models of motor neuron disease, such as progressive motor neuronopathy ( $p m n)$ or the transgenic SOD1 G93A model of amyotrophic lateral sclerosis, apoptosis of neuronal cell bodies was blocked by expression of the anti-apoptotic Bcl-2 gene or knock-out of the proapoptotic Bax gene (Sagot et al. 1995; Gould et al. 2006). In each case, degeneration of the neuronal processes continued unimpeded and disease progression was unaffected. ACR-2(L/S)-induced cell death clearly occurs independently of the apoptotic pathway. However, it is interesting to note that we also observe a progressive destabilization of the motor neuron processes that leads to paralysis even under conditions when death of the cell body is attenuated. Therefore, NMJ denervation that occurs independently of the death of neuronal cell bodies is the dominant feature shared across each of these cases. In the future, it will be interesting to uncover the molecular events leading to degeneration of the neuronal processes and determine whether elements of the degenerative process are conserved across these diverse models.

\section{References}

Brenner S (1974) The genetics of Caenorhabditis elegans. Genetics 77:71-94. Brockie PJ, Mellem JE, Hills T, Madsen DM, Maricq AV (2001) The C. elegans glutamate receptor subunit NMR-1 is required for slow NMDAactivated currents that regulate reversal frequency during locomotion. Neuron 31:617-630.

Chalfie M, Tu Y, Euskirchen G, Ward WW, Prasher DC (1994) Green fluorescent protein as a marker for gene expression. Science 263:802-805.

Chase DL, Pepper JS, Koelle MR (2004) Mechanism of extrasynaptic dopamine signaling in Caenorhabditis elegans. Nat Neurosci 7:1096-1103.

Cinar H, Keles S, Jin Y (2005) Expression profiling of GABAergic motor neurons in Caenorhabditis elegans. Curr Biol 15:340-346.

Culetto E, Baylis HA, Richmond JE, Jones AK, Fleming JT, Squire MD, Lewis JA, Sattelle DB (2004) The Caenorhabditis elegans unc-63 gene encodes a levamisole-sensitive nicotinic acetylcholine receptor alpha subunit. J Biol Chem 279:42476-42483.

Dani JA, Bertrand D (2007) Nicotinic acetylcholine receptors and nicotinic cholinergic mechanisms of the central nervous system. Annu Rev Pharmacol Toxicol 47:699-729.

Danial NN, Korsmeyer SJ (2004) Cell death: critical control points. Cell 116:205-219.

Davis MW, Hammarlund M, Harrach T, Hullett P, Olsen S, Jorgensen EM (2005) Rapid single nucleotide polymorphism mapping in C. elegans. BMC Genomics 6:118.

Denzel A, Molinari M, Trigueros C, Martin JE, Velmurgan S, Brown S, Stamp G, Owen MJ (2002) Early postnatal death and motor disorders in mice 
congenitally deficient in calnexin expression. Mol Cell Biol 22:73987404.

Driscoll M, Gerstbrein B (2003) Dying for a cause: invertebrate genetics takes on human neurodegeneration. Nat Rev Genet 4:181-194.

Eimer S, Gottschalk A, Hengartner M, Horvitz HR, Richmond J, Schafer WR, Bessereau JL (2007) Regulation of nicotinic receptor trafficking by the transmembrane Golgi protein UNC-50. EMBO J 26:4313-4323.

Ellgaard L, Frickel EM (2003) Calnexin, calreticulin, and ERp57: teammates in glycoprotein folding. Cell Biochem Biophys 39:223-247.

Ellis HM, Horvitz HR (1986) Genetic control of programmed cell death in the nematode C. elegans. Cell 44:817-829.

Festjens N, Vanden Berghe T, Vandenabeele P (2006) Necrosis, a wellorchestrated form of cell demise: signalling cascades, important mediators and concomitant immune response. Biochim Biophys Acta 1757:1371-1387.

Fleming JT, Squire MD, Barnes TM, Tornoe C, Matsuda K, Ahnn J, Fire A, Sulston JE, Barnard EA, Sattelle DB, Lewis JA (1997) Caenorhabditis elegans levamisole resistance genes lev-1, unc-29, and unc-38 encode functional nicotinic acetylcholine receptor subunits. J Neurosci 17:58435857.

Francis MM, Evans SP, Jensen M, Madsen DM, Mancuso J, Norman KR, Maricq AV (2005) The Ror receptor tyrosine kinase CAM-1 is required for ACR-16-mediated synaptic transmission at the C. elegans neuromuscular junction. Neuron 46:581-594.

Golstein P, Kroemer G (2007) Cell death by necrosis: towards a molecular definition. Trends Biochem Sci 32:37-43.

Gottschalk A, Almedom RB, Schedletzky T, Anderson SD, Yates JR 3rd, Schafer WR (2005) Identification and characterization of novel nicotinic receptor-associated proteins in Caenorhabditis elegans. EMBO J 24:2566-2578.

Gould TW, Buss RR, Vinsant S, Prevette D, Sun W, Knudson CM, Milligan CE, Oppenheim RW (2006) Complete dissociation of motor neuron death from motor dysfunction by Bax deletion in a mouse model of ALS. J Neurosci 26:8774-8786.

Grosskreutz J, Van Den Bosch L, Keller BU (2010) Calcium dysregulation in amyotrophic lateral sclerosis. Cell Calcium 47:165-174.

Hallam S, Singer E, Waring D, Jin Y (2000) The C. elegans NeuroD homolog cnd-1 functions in multiple aspects of motor neuron fate specification. Development 127:4239-4252.

Hammarlund M, Jorgensen EM, Bastiani MJ (2007) Axons break in animals lacking beta-spectrin. J Cell Biol 176:269-275.

Heintz N, Zoghbi HY (2000) Insights from mouse models into the molecular basis of neurodegeneration. Annu Rev Physiol 62:779-802.

Hengartner MO, Ellis RE, Horvitz HR (1992) Caenorhabditis elegans gene ced-9 protects cells from programmed cell death. Nature 356:494-499.

Hruska M, Nishi R (2007) Cell-autonomous inhibition of alpha 7-containing nicotinic acetylcholine receptors prevents death of parasympathetic neurons during development. J Neurosci 27:11501-11509.

Hruska M, Keefe J, Wert D, Tekinay AB, Hulce JJ, Ibañez-Tallon I, Nishi R (2009) Prostate stem cell antigen is an endogenous lynx1-like prototoxin that antagonizes alpha7-containing nicotinic receptors and prevents programmed cell death of parasympathetic neurons. J Neurosci 29:1484714854.

Jones AK, Davis P, Hodgkin J, Sattelle DB (2007) The nicotinic acetylcholine receptor gene family of the nematode Caenorhabditis elegans: an update on nomenclature. Invert Neurosci 7:129-131.

Jospin M, Qi YB, Stawicki TM, Boulin T, Schuske KR, Horvitz HR, Bessereau JL, Jorgensen EM, Jin Y (2009) A neuronal acetylcholine receptor regulates the balance of muscle excitation and inhibition in Caenorhabditis elegans. PLoS Biol 7: e1000265.

Knobel KM, Davis WS, Jorgensen EM, Bastiani MJ (2001) UNC-119 suppresses axon branching in C. elegans. Development 128:4079-4092.

Kwak S, Weiss JH (2006) Calcium-permeable AMPA channels in neurodegenerative disease and ischemia. Curr Opin Neurobiol 16:281-287.

Labarca C, Nowak MW, Zhang H, Tang L, Deshpande P, Lester HA (1995) Channel gating governed symmetrically by conserved leucine residues in the M2 domain of nicotinic receptors. Nature 376:514-516.
Labarca C, Schwarz J, Deshpande P, Schwarz S, Nowak MW, Fonck C, Nashmi R, Kofuji P, Dang H, Shi W, Fidan M, Khakh BS, Chen Z, Bowers BJ, Boulter J, Wehner JM, Lester HA (2001) Point mutant mice with hypersensitive alpha 4 nicotinic receptors show dopaminergic deficits and increased anxiety. Proc Natl Acad Sci U S A 98:2786-2791.

Mattson MP, LaFerla FM, Chan SL, Leissring MA, Shepel PN, Geiger JD (2000) Calcium signaling in the ER: its role in neuronal plasticity and neurodegenerative disorders. Trends Neurosci 23:222-229.

Mesaeli N, Nakamura K, Zvaritch E, Dickie P, Dziak E, Krause KH, Opas M, MacLennan DH, Michalak M (1999) Calreticulin is essential for cardiac development. J Cell Biol 144:857-868.

Miwa JM, Stevens TR, King SL, Caldarone BJ, Ibanez-Tallon I, Xiao C, Fitzsimonds RM, Pavlides C, Lester HA, Picciotto MR, Heintz N (2006) The prototoxin lynxl acts on nicotinic acetylcholine receptors to balance neuronal activity and survival in vivo. Neuron 51:587-600.

Orb S, Wieacker J, Labarca C, Fonck C, Lester HA, Schwarz J (2004) Knockin mice with Leu9'Ser alpha4-nicotinic receptors: substantia nigra dopaminergic neurons are hypersensitive to agonist and lost postnatally. Physiol Genomics 18:299-307.

Orr-Urtreger A, Broide RS, Kasten MR, Dang H, Dani JA, Beaudet AL, Patrick JW (2000) Mice homozygous for the L250T mutation in the alpha7 nicotinic acetylcholine receptor show increased neuronal apoptosis and die within 1 day of birth. J Neurochem 74:2154-2166.

Rand JB (2007) Acetylcholine. WormBook 1-21.

Rao RV, Ellerby HM, Bredesen DE (2004) Coupling endoplasmic reticulum stress to the cell death program. Cell Death Differ 11:372-380.

Revah F, Bertrand D, Galzi JL, Devillers-Thiéry A, Mulle C, Hussy N, Bertrand S, Ballivet M, Changeux JP (1991) Mutations in the channel domain alter desensitization of a neuronal nicotinic receptor. Nature 353:846-849.

Richmond JE, Jorgensen EM (1999) One GABA and two acetylcholine receptors function at the C. elegans neuromuscular junction. Nat Neurosci 2:791-797.

Ruaud AF, Bessereau JL (2006) Activation of nicotinic receptors uncouples a developmental timer from the molting timer in C. elegans. Development 133:2211-2222.

Sagot Y, Dubois-Dauphin M, Tan SA, de Bilbao F, Aebischer P, Martinou JC, Kato AC (1995) Bcl-2 overexpression prevents motoneuron cell body loss but not axonal degeneration in a mouse model of a neurodegenerative disease. J Neurosci 15:7727-7733.

Sattler R, Tymianski M (2001) Molecular mechanisms of glutamate receptor-mediated excitotoxic neuronal cell death. Mol Neurobiol 24:107-129.

Sulston JE, Horvitz HR (1977) Post-embryonic cell lineages of the nematode, Caenorhabditis elegans. Dev Biol 56:110-156.

Syntichaki P, Xu K, Driscoll M, Tavernarakis N (2002) Specific aspartyl and calpain proteases are required for neurodegeneration in C. elegans. Nature 419:939-944.

Szydlowska K, Tymianski M (2010) Calcium, ischemia and excitotoxicity. Cell Calcium 47:122-129.

Touroutine D, Fox RM, Von Stetina SE, Burdina A, Miller DM 3rd, Richmond JE (2005) acr-16 encodes an essential subunit of the levamisole-resistant nicotinic receptor at the Caenorhabditis elegans neuromuscular junction. J Biol Chem 280:27013-27021.

Treinin M, Chalfie M (1995) A mutated acetylcholine receptor subunit causes neuronal degeneration in C. elegans. Neuron 14:871-877.

Wicks SR, Yeh RT, Gish WR, Waterston RH, Plasterk RH (2001) Rapid gene mapping in Caenorhabditis elegans using a high density polymorphism map. Nat Genet 28:160-164.

Xu K, Tavernarakis N, Driscoll M (2001) Necrotic cell death in C. elegans requires the function of calreticulin and regulators of $\mathrm{Ca}^{2+}$ release from the endoplasmic reticulum. Neuron 31:957-971.

Zuo J, De Jager PL, Takahashi KA, Jiang W, Linden DJ, Heintz N (1997) Neurodegeneration in Lurcher mice caused by mutation in delta2 glutamate receptor gene. Nature 388:769-773. 